\title{
Recent update on crosslinked polyethylene in total hip arthroplasty
}

\author{
Jean Langlois ${ }^{1,2, *}$ and Moussa Hamadouche ${ }^{3}$ \\ ${ }^{1}$ Centre Orthopédique Santy, 24, avenue Paul Santy, 69008 Lyon, France \\ 2 Hôpital Privé Jean-Mermoz, 55, avenue Jean-Mermoz, 69008 Lyon, France \\ 3 Département de Chirurgie Orthopédique, Université Paris-Descartes, Assistance Publique-Hôpitaux de Paris, Hôpital Cochin, 27, rue du \\ Faubourg Saint-Jacques, 75014 Paris, France
}

Received 22 April 2020, Accepted 23 April 2020, Published online 15 May 2020

\begin{abstract}
More than two decades after their clinical introduction, crosslinked polyethylenes (XLPE) have been widely adopted. Though concerns were initially raised regarding oxidation and brittleness, on a large scale, the first generation of XLPE continues to be highly effective 15 years after the surgery, even in a young and active population. Remelted XLPE might display lower wear rates than annealed XLPE. Second generation XLPEs, not only including sequentially irradiated and annealed but also associated with antioxidants, demonstrate encouraging short- to mid-term results. Registry data support clinical trial reports. Even in less favorable settings (lipped liners, dual mobility cups, revision surgery, hip resurfacing) results are promising. However, failures (fractures) have already been described. Therefore, a high level of surveillance remains crucial.
\end{abstract}

Key words: Total hip arthroplasty, Highly crosslinked polyethylene, Wear, Oxidation, Fatigue resistance.

\section{Introduction}

Primary total hip arthroplasty (THA) has proven to be highly effective for end-stage hip osteoarthritis. The majority of implants are expected to last over 20 years. Driven by these results, there has been a decline in the average age of THA candidates. Younger patients represent a unique challenge, as they demand longer implant survivorship, while their physical activity creates increased cumulative stress on the implants. Besides, obesity is reaching epidemic proportions, with increasing demand for THA, and represents an additional challenge for the choice of bearing surface.

With the number of primary THA procedures expected to grow, and the cost-effectiveness being scrutinized, minimizing early complications, such as instability, while reducing wear and extending component survivorship, continues to draw heavy attention. Selection of the proper bearing material is therefore a key to optimize both short- and long-term results.

With the widespread adoption of crosslinked polyethylene (XLPE), particle osteolysis and aseptic loosening has become less common than in historical series, and other causes (dislocation, infection) have come to account for more than half of the revisions [1]. However, concerns with the long-term results of XLPE have been raised, due to risk of fatigue fracture, oxidation, and wear particles having a different bioreactivity profile

\footnotetext{
*Corresponding author: drjeanlanglois@gmail.com
}

that could result in more aggressive osteolysis, even in low wear rate settings. After two decades of utilization, it became essential to review some of the most relevant and recent clinical studies about XLPE.

\section{Long-term wear, osteolysis, and survivorship}

Crosslinked polyethylene has demonstrated during the first decade by all means lower wear rates than conventional polyethylene (CPE) [2-4]. But publications are scarce regarding outcomes over 15 years of follow-up, when complications, such as wear or oxidation may occur.

At a mean follow-up of 16 years, Bryan et al. [5] reported results of 237 patients under 50 years of age (273 hips, 216 melted XLPE versus $57 \mathrm{CPE}$ ). Using a manual method, the mean linear CPE wear rate was $0.23 \mathrm{~mm} /$ year, while the XLPE group had no detectable wear. Forty-four patients (77\%) in the CPE group had evidence of osteolysis compared to no osteolysis in the XLPE group. They were six revisions for wear in CPE group $(10.5 \%)$ compared to none in the XLPE group $(P<0.001)$. Rames et al. [6] found similar results, evaluating 54 hips in a young population receiving a melted XLPE. At average 15 years, wear rate was $0.0185 \mathrm{~mm} /$ year. No liner fracture, no osteolysis, and no loosening were reported. The survivorship with all causes of revision as endpoint was $97.8 \%$. Hopper et al. [7] compared the results of 230 hips randomized 
to receive either a $50 \mathrm{kGy}$ melted XLPE or a CPE. The 15 -year wear-related revision rate was lower in the XLPE group (0\%) than in the CPE group $(12 \% ; P<0.001)$. Among unrevised THAs, XLPE wear rate $(0.03 \mathrm{~mm} /$ year $)$ was lower than CPE wear rate $(0.17 \mathrm{~mm} /$ year; $P<0.001)$. Osteolysis of any size was noted among $9 \%$ of the XLPE hips versus $46 \%$ of the CPE hips $(P<0.001)$. Similar results with melted XLPE outperforming CPE with at least 15 years of follow-up were reported by Moon et al. [8]. Since plain radiographs have a sensitivity close to $40 \%$ [9], osteolysis has been specifically assessed by Fukui et al. [10] with computed tomography and 3D multiplanar reconstruction images. Data from 105 primary THA using a melted XLPE liner (in an uncemented cup with two screws, against $26 \mathrm{~mm}$ zirconia femoral head) were extracted at a mean follow-up of 15.9 years. No obvious osteolysis in the acetabulum or femur in any patient was detected.

Gaudiani et al. [11] evaluated 57 consecutive hips with a mean follow-up of 14 years using annealed XLPE and found it to have excellent long-term behavior: a $0.032 \mathrm{~mm} /$ year wear rate, no observed osteolysis, no implant failure because of loosening on either the acetabular or femoral side. Conversely, Tsukamoto et al. [12] warned of possible excessive wear for an annealed XLPE between 10 and 15 years. This annealed XLPE demonstrated no advantage in the wear rate or in the incidence of osteolysis at 15 years, despite having superior wear resistance up to 10 years, as compared to CPE. No liner fracture occurred. The hypotheses were that, either the level of crosslinking was not sufficient enough to reduce wear beyond 10 years, or oxidation occurred, accelerating material failure and increasing wear rate. The degree of oxidation of the explants was unfortunately not analyzed. On a large scale, the first generation of XLPE continues to be highly effective 15 years after the surgery, even in a young and active population. Remelted XLPE might turn to display lower wear rates than annealed XLPE.

Gaudiani et al. [13] demonstrated encouraging results at mean follow-up of 6 years with the sequentially irradiated and annealed PE, with low wear rates (0.015 mm/year). Moreover, they were unable to detect a significant difference in wear rates with $32-$ or $36-\mathrm{mm}$, metal and ceramic heads. Radiographic analysis revealed no instance of osteolysis. Bonutti et al. [14] evaluated wear rate of the same sequentially irradiated and annealed PE with a mean follow-up of 10.3 years (118 patients, mean age of 63 years) and found it to be extremely low (0.014 mm/year), with no osteolysis. The 10-year survivorship was $98.3 \%$. Deckard and Meneghini [15], using both ceramic and cobalt-chrome heads, from 32 to 40-mm diameters, found surprisingly higher wear rates of sequentially annealed PE (0.095 mm/year, with minimum 5-year follow-up), close to the $0.1 \mathrm{~mm} /$ year which is known as the osteolysis threshold.

Extended reviews have been published about XLPE including vitamin $\mathrm{E}$ or other antioxidants [16, 17], but to date, main data are collected from ex vivo experiments or clinical studies with less than 5-year follow-up. At this short term, vitamin E poly has not proved any clinically significant advantage in terms of patient function, wear or revision rate as compared to first generation of XLPE. Galea et al. [18] published data from a multicenter study assessing the midterm behavior of a vitamin E infused XLPE. Implant survivorship was $97.1 \%$ at
5 years. They found a very low wear rate $(0.01 \mathrm{~mm} /$ year $)$, with no evidence of osteolysis or aseptic loosening. Regression analysis showed that metal (versus ceramic) femoral head was predictive of increase wear, as opposed to cup position, femoral head size, or BMI. Lindalen et al. [19] measured at 6-year follow-up wear, with radiostereometric analysis in THAs articulating delta ceramic heads $(32-36 \mathrm{~mm})$ and vitamin infused XLPE. They found a mean $0.015 \mathrm{~mm} /$ year wear rate. As conclusion, Vitamin E XLPE has encouraging early results, but long-term follow-up will be required before definitive conclusions can be provided.

\section{Risk factors of wear}

Numerous factors have been associated with greater wear using CPE. Whether these relationships hold true with XLPE is still a matter of debate. Regarding patient-related factors, Rames et al. [6] showed no statistically significant difference in terms of wear rates between a subgroup of highly active patients (UCLA score 8-10) compared to a lower demand group (UCLA score 1-7).

Lachiewicz et al. [20] evaluated at a mean follow-up of 11 years whether femoral head size had an influence on wear of melted XLPE. They reported about a cohort of 84 hips, using 26, 28, 32, 36 and $40 \mathrm{~mm}$ cobalt-chrome heads. As a result of surgical indications, the patients with $36-/ 40-\mathrm{mm}$ head were significantly older (75 years) than those with smaller heads (58 years; $P<0.001$ ). With the numbers available, the authors found no association between femoral head size and linear wear rate. The same authors then selected 107 hips (mean patient age 76 years) with larger heads (36-40 mm heads). At a mean follow-up of 8 years, they found no wear difference between 36 and 40-mm [21]. Likewise, Lindalen et al. [19] found no difference between 32 and 36-mm ceramic heads articulating in front of a vitamin E XLPE at 6-year follow-up.

In order to minimize the production of wear particles, different femoral head materials have been tested to articulate with XLPE. After 5-year follow-up, Jassim et al. [22] reported on $32 \mathrm{~mm}$ heads against melted XLPE and found no difference between oxidized zirconium and cobalt-chrome. Similarly, Sato et al. [23] showed no difference 6.3 years after the index surgery between cobalt-chrome, alumina and zirconia ceramic heads (22 or $26 \mathrm{~mm}$ diameters). With 12-year follow-up. Garvin et al. [24] found no difference in wear rates between cobalt-chrome, ceramic and oxinium with $28 \mathrm{~mm}$ heads. In conclusion, the 10-year cumulative revision rates reported in the Australian Registry (2016 Annual report) were similar for all three bearing materials on XLPE, at $3.2 \%$ for ceramicized metal, $4.4 \%$ for ceramic, and $4.3 \%$ for metal [25].

Cheung et al. [26] were the first to demonstrate, after mean follow-up of 13 years, a significant relationship between cup positioning (inclination and anteversion) and linear wear rates using melted XLPE. Except age and comorbidity, other patient demographics factors, such as gender, body weight, BMI, UCLA activity score, alcohol, or steroid intake, but also liner thickness or femoral offset, had no influence on wear rates in that study. Conversely, Moon et al. [8] failed to demonstrate any statistical correlation between wear and cup position. 
In conclusion, acetabular component orientation probably keeps affecting wear rate of XLPE liners. However, in contrast to $\mathrm{CPE}$, it remains less evident that patients' activity, head size, or material, play a clinically relevant role, based on the midto long-term studies currently available.

\section{Registry data}

A recent report based on the Australian registry revealed a significantly lower cumulative rate of revision using XLPE (6.2\%) when compared to CPE (11.7\%) at average 16-year follow-up [27]. This difference prevailed within subgroup analyses, such as cup design, femoral head material or diameter. This discrepancy was further exaggerated when stratified for cohort of patients under 55 years of age (revision rate was $17.4 \%$ for CPE, versus $6.6 \%$ for XLPE). The authors concluded that the benefit of XLPE was evident both early and late, with a reduced rate of revisions due to dislocation (XLPE allowing a sound use of larger femoral heads) and to wear-related issues.

Similar differences were reported from the 2019 New Zealand Joint Registry [28]. They showed that using ceramic femoral heads, the revision rate per 100 component years for CPE was 0.77 , in contrast to the XLPE rate of 0.54 . For those cases using a metal femoral head the corresponding figures were 0.76 for the CPE and 0.56 for the XLPE.

Swedish registry data (from the 2013 report) demonstrated a lower overall risk of revision at 12 years for XLPE compared with CPE (1.9\% and 4.3\%, respectively) [29]. Regarding revision risk with at least 7.5 years of follow-up, data analyses from the Nordic Arthroplasty Register Association showed evidence that specific cup designs and fixation type (cemented or not) may affect the implant survivorship of the implant, as much as the PE formulation itself [30].

A recent study based on the UK National Joint Registry found that PE liners with a total radiation dose of $\geq 50 \mathrm{kGy}$ demonstrate best survival at 14-year follow-up [31]. Moreover, highly irradiated liners (100 kGy or above) were not associated with an additional reduction in the risk of revision, when compared to moderately irradiated liners (50-100 kGy). Stabilization with vitamin $\mathrm{E}$ and heating above melting point performed best. To our knowledge, no long-term registry data are available regarding to XLPE including antioxidants.

\section{Less favorable settings}

\section{Revision}

Revision surgery exposes to third-body wear and less accurate component positioning. Lim et al. [32] evaluated 63 revision procedures using a melted XLPE. At 11-year followup, three hips had radiolucent lines around the cup, without evidence of loosening. On the femoral side, 5 hips had radiolucent lines in zones 1 and 7, but no subsidence. The mean linear wear rate was $0.029 \mathrm{~mm} /$ year. Five hips required re-revision, including 1 cup loosening, one recurrent dislocation, and 3 infections. None of the liners was revised due to polyethylene wear or mechanical failure. As confirmed by another publication [22], no difference was noted between metal and ceramic head when articulating with XLPE. Consequently, it appears that using an XLPE acetabular liner might be more important in reducing wear than the choice of femoral head bearing. It might represent an important key, when dealing in revisions with damaged tapers and the risk of ceramic head fracture.

\section{Elevated-rim and offset liners}

Concerns about XLPE brittleness may raise with specific thin designs, such as elevated-rim or offset [33] liners. These constructs may be more vulnerable to rim cracking or fracture due to impingement, potentially leading to excessive wear and loosening. However, the evidence for this hypothesis remains yet inconclusive. Shin et al. [34] were among the first to compare standard versus elevated-rim melted XLPE liners. At 15-year follow-up, wear rates were low $(<0.03 \mathrm{~mm} /$ year $)$ and not significantly different between groups. Survivorships for all-cause reasons were excellent $(>96 \%)$ and not significantly different. One case $(1.3 \%)$ of osteolysis was confirmed in the standard group, whereas no osteolysis was observed in the elevated-rim group. Similarly, a recent analysis based on the Australian registry [35] found that XLPE lipped liners were not associated with an increased revision rate for aseptic loosening at a mean of 5 years. Revisions for breakage of the acetabular liner were extremely rare, with 11 for lipped liners $(0.009 \%)$ and four for standard liners $(0.006 \%)$. For Davis et al. [31] the use of asymmetrical (lipped) XLPE liners was actually associated with reduced risk of revision for any reason, for aseptic loosening (possibly the result of confounding variables, such as surgical approach, implant design and positioning), and for reasons other than aseptic loosening.

\section{Dual mobility}

The concept of dual mobility is also mechanically demanding for the PE mobile insert, since it has to combine the theoretical wear resistance with sufficient elasticity to allow the initial passage of head through the restriction zone. These concerns were confirmed recently by biomechanical experiments [36]. They suggested that during the snap-fit head introduction, the impaction in force would overcome the ultimate strength of the XLPE. Therefore, nonreversible plastic deformation of the restriction zone and cracks would occur, leading to a loss of retentive power. The first finding was that femoral head snap-fit did not generate more or wider cracks in the retentive area of annealed or remelted XLPE than of CPE. Second important finding was that, as compared to CPE or annealed XLPE groups, for the remelted XLPE group, femoral head extraction force was significantly lower when cracks were present. It has to be determined if this difference is of clinical relevancy.

Epinette et al. [37] were the first to evaluate performance of a dual mobility acetabular system with XLPE (sequentially irradiated and annealed) with midterm follow-up. This multicenter prospective study included 321 young patients (mean age 48 years). There was no dislocation, nor any intra-prosthetic dissociation. Two acetabular shells were revised for neck-rim implant impingement without dislocation. Survivorship for all-cause was $97.5 \%$ at 5 years. 
Short-term retrieval data from 33 XLPE (sequentially irradiated and annealed) dual mobility components (revised for non-mechanical failure) from D'Apuzzo et al. [38] suggested that although motion occurs at both bearing articulations, the inner bearing motion dominates. Second, the locking mechanism remained intact in the short term regardless of liner size. Lever out tests to dislocate the femoral head from the mobile PE (intraprosthetic dislocation) were performed on retrievals in order to challenge the locking mechanism. Results did not demonstrate any relationship between length of implantation (mean 6 months, range 0.06 to 26) and dislocation load. Taken altogether, these results suggest that a second generation of XLPE such as sequentially annealed or vitamin E-doped XLPE might probably constitute the most suitable material for dual mobility systems.

\section{Resurfacing}

Encouraging midterm results have been reported with metalon-XLPE hip resurfacing using "two-piece" acetabular components (a XLPE liner fixed in a titanium shell) [39, 40]. But these thick constructs can lead to undesirable acetabular bone removal, and expose to liner dissociation or thin XLPE fracture. For that purpose, Treacy et al. [41] recently reported preliminary data (88 hips, mean follow-up 1.6 years, 0.7-3.9) about a novel design of hip resurfacing arthroplasty using a direct-to-bone cementless mono-bloc XLPE component, in a cohort of 84 patients ( $73 \%$ of women, mean age 56 years) currently contraindicated for metal-on-metal resurfacing. No early failure occurred. The short-term functional results in this small cohort are similar with those of THA. Radiographs showed one head-neck junction radiolucency, but no osteolysis, component migration, or femoral neck thinning. However, wear and survival rates data with longer term follow-up will be needed.

\section{Crosslinked polyethylene failures}

Crosslinking processes were developed to improve wear resistance, however balanced with brittleness and decreased fracture toughness. Several clinical reports have been published about fractures of XLPE liners ([42-44], non-exhaustive list). More recently Ast et al. [45] reviewed all the voluntary reports of one specific non-constrained, non-offset melted fractured liner to the US FDA, and confronted these findings to the current literature, to determine if any risk factors could be identified. The research was completed between 1999 and 2013. There have been 74 reports of fractured liners during this period, and all cases required revision surgery. The average time in situ was 27 months (range 1-96). No correlation was detected between the material thickness and the time in situ. Most cases (69\%) reported small acetabular shells $(\leq 54 \mathrm{~mm})$ combined with large diameter heads $(\geq 36 \mathrm{~mm})$. Liners fractured were less than $7 \mathrm{~mm}$ thick at the weight bearing area (82\% of the cases), and/or $<4.7 \mathrm{~mm}$ thick at the rim $(97 \%$ of the cases). It should be remembered that the difference in thickness between the weight-bearing area and the rim (the area that fractured in the majority of the cases) is more pronounced as the diameter of the femoral head increases. As an example, for a $52-\mathrm{mm}$ shell, the difference is $1.6 \mathrm{~mm}$ for a $28-\mathrm{mm}$ head, but raises up to $3.3 \mathrm{~mm}$ for a $36-\mathrm{mm}$ head.
As a conclusion, fractures are likely to be multifactorial issues: the inherent mechanical characteristics of remelted HXLPE liners, liner/shell designs with stress concentrators $[46,47]$, trauma or dislocation, malposition of the shell, neckliner impingement, and the use of thin polyethylene liners. These warnings should probably be extended to any PE formulation, even the more recent and resilient ones, since liner fractures have already been described [48, 49].

Also instructive in a different manner, is the failure report of a specific formulation of XLPE: a moderately cross-linked using two doses of $25 \mathrm{kGy}$, for a total irradiation dose of $50 \mathrm{kGy}$. No thermal treatment to quench free-radicals is applied. And the sterilization is based on gamma irradiation. This polyethylene liner has a specific design that is considered to be unique by the manufacturer, i.e. the "polar-locking" mechanism that is combined with antirotational tabs. Kahlenberg et al. [50] identified five cases (among 204 primary THA) of severe polyethylene wear $(0.265 \mathrm{~mm} / \mathrm{year}$ rate $)$ and osteolysis which occurred within 5 years of the index surgery using this specific PE. Ceramic heads with $36-\mathrm{mm}$ diameter were used in all the cases. All patients were men, with excellent early results and high activity scores (mean UCLA 7.4). Socket abduction was always less than $44^{\circ}$. Retrieved liners had grossly visible wear but no discoloration suggestive of oxidation. Similar reports (12 cases), with no identifiable factor, have been published recently [51], and the manufacturer revealed 22 reported cases of such failure between 2009 and 2019. Hypotheses for this usual early excessive wear are manufacturing characteristics of the polyethylene liner itself or the locking mechanism, or a combination of both. Further investigations are underway. This example proves that surgeon vigilance, along with registry data and scientific publication, continues to be invaluable.

\section{Conclusion}

There is a long list of both outstanding and disastrous innovations in the field of hip replacement, especially with bearing materials (PTFE, Hylamer, Yttria-stabilized tetragonal zirconia heads, metal-on-metal) $[52,53]$. The ideal bearing surface has yet to come [54]. The current evolution of PE might lead to one of them. Given optimistic estimates, the US might save one billion dollars over a 15-year duration with the use of XLPE [55], assuming this product would be responsible for a $40 \%$ reduced rate of all-cause revision.

But in the search for this breakthrough material, several statements should rule:

- Each PE is a product with a specific manufacturing process and should be evaluated individually. Pooling all the polys into generation boxes might be an irrelevant shortcut.

- Since THA standards have been brought to such a high level, any modification should come with solid arguments (i.e. long-term results, from non-designer teams) before widespread.

- Keeping a high level of post market surveillance is crucial, including prospective RCT, national registries data, but also retrieval analyses with standardized protocols. 
There is no doubt that we should keep the innovation pipeline running. But a healthy skepticism should always prevail, by means of stepwise introduction of new technology [56].

\section{Conflict of interest}

The authors declare that they have no conflict of interest.

\section{Financial disclosure}

Jean Langlois is a paid consultant for Corin and Depuy. Moussa Hamadouche is a paid consultant and receives royalties from Medacta.

\section{References}

1. Haynes JA, Stambough JB, Sassoon AA, Johnson SR, Clohisy JC, Nunley RM (2016) Contemporary surgical indications and referral trends in revision total hip arthroplasty: a 10-year review. J Arthroplasty 31, 622-625.

2. Lachiewicz PF, Kleeman LT, Seyler T (2018) Bearing surfaces for total hip arthroplasty. J Am Acad Orthop Surg 26, 45-57.

3. Singh G, Klassen R, Howard J, Naudie D, Teeter M, Lanting B (2018) Manufacturing, oxidation, mechanical properties and clinical performance of highly cross-linked polyethylene in total hip arthroplasty. Hip Int 28, 573-583.

4. Shi J, Zhu W, Liang S, Li H, Li S (2019) Cross-linked versus conventional polyethylene for long-term clinical outcomes after total hip arthroplasty: a systematic review and meta-analysis. J Invest Surg, 1-11.

5. Bryan AJ, Calkins TE, Karas V, Culvern C, Nam D, Della Valle CJ (2019) Primary total hip arthroplasty in patients less than 50 years of age at a mean of 16 years: highly crosslinked polyethylene significantly reduces the risk of revision. J Arthroplasty 34, S238-S241.

6. Rames RD, Stambough JB, Pashos GE, Maloney WJ, Martell JM, Clohisy JC (2019) Fifteen-year results of total hip arthroplasty with cobalt-chromium femoral heads on highly cross-linked polyethylene in patients 50 years and less. J Arthroplasty 34, 1143-1149.

7. Hopper RH Jr, Ho H, Sritulanondha S, Williams AC, Engh CA Jr (2018) Otto Aufranc Award: Crosslinking reduces THA wear, osteolysis, and revision rates at 15-year followup compared with noncrosslinked polyethylene. Clin Orthop Relat Res 476, 279-290.

8. Moon NH, Shin WC, Do MU, Kang SW, Lee SM, Suh KT (2020) Wear and osteolysis outcomes for highly cross-linked polyethylene in primary total hip arthroplasty compared with conventional polyethylene: a 15 - to 18-year single-centre follow-up study. Hip Int. 1120700019896970 . Advance online publication.

9. Claus AM, Engh CA Jr, Sychterz CJ, Xenos JS, Orishimo KF, Engh CA Sr (2003) Radiographic definition of pelvic osteolysis following total hip arthroplasty. J Bone Joint Surg Am 85, 1519-1526.

10. Fukui K, Kaneuji A, Wang X, Ichiseki T, Matsumoto T, Kawahara N (2019) Computed tomographic osteolytic analysis of a first-generation remelted highly cross-linked polyethylene in total hip arthroplasty-at a minimum of 15 -year follow-up. J Arthroplasty 35, 1417-1423.
11. Gaudiani MA, Ranawat AS, Ranawat CS (2018) Wear analysis of highly cross-linked polyethylene in young and active patients at average fourteen years: a concise follow-up of a previous report. J Arthroplasty 33, 586-589.

12. Tsukamoto M, Ohnishi H, Mori T, Kawasaki M, Uchida S, Sakai A (2017) Fifteen-year comparison of wear and osteolysis analysis for cross-linked or conventional polyethylene in cementless total hip arthroplasty for hip dysplasia-a retrospective cohort study. J Arthroplasty 32, 161-165.e1.

13. Gaudiani MA, White PB, Ghazi N, Ranawat AS, Ranawat CS (2018) Wear rates with large metal and ceramic heads on a second generation highly cross-linked polyethylene at mean 6-year follow-up. J Arthroplasty 33, 590-594.

14. Bonutti PM, Mesko JW, Ramakrishnan R (2018) Long-term wear data from a prospective multicenter study of secondgeneration highly cross-linked polyethylene inserts in total hip arthroplasty. Orthopedics 41, e529-e533.

15. Deckard ER, Meneghini RM (2019) Femoral head penetration rates of second-generation sequentially annealed highly crosslinked polyethylene at minimum five years. J Arthroplasty 34, 781-788.

16. Lambert B, Neut D, van der Veen HC, Bulstra SK (2019) Effects of vitamin $\mathrm{E}$ incorporation in polyethylene on oxidative degradation, wear rates, immune response, and infections in total joint arthroplasty: a review of the current literature. Int Orthop 43, 1549-1557.

17. Wyatt MC, Roberto A, Foxall-Smi M, Beswick AD, Kenutsor SK, Whitehouse MR (2019) Does vitamin E highly-crosslinked polyethylene convey an advantage in primary total hip replacement? A systematic review and meta-analysis. Hip Int, 1120700019858335. Advance online publication.

18. Galea VP, Connelly JW, Shareghi B, Kärrholm J, Sköldenberg O, Salemyr M, Laursen MB, Muratoglu O, Bragdon C, Malchau H (2018) Evaluation of in vivo wear of vitamin E-diffused highly crosslinked polyethylene at five years: a multicentre radiostereometric analysis study. Bone Joint J 100-B, 1592-1599.

19. Lindalen E, Thoen PS, Nordsletten L, Høvik $\varnothing$, Röhrl SM (2019) Low wear rate at 6-year follow-up of vitamin E-infused cross-linked polyethylene: a randomised trial using 32 - and 36-mm heads. Hip Int 29, 355-362.

20. Lachiewicz PF, Soileau ES, Martell JM (2016) Wear and osteolysis of highly crosslinked polyethylene at 10 to 14 years: the effect of femoral head size. Clin Orthop Relat Res 474, 365371.

21. Lachiewicz PF, O’Dell JA, Martell JM (2018) Large metal heads and highly cross-linked polyethylene provide low wear and complications at 5-13 years. J Arthroplasty 33, 2187-2191.

22. Jassim SS, Patel S, Wardle N, Tahmassebi J, Middleton R, Shardlow DL, Stephen A, Hutchinson J, Haddad FS (2015) Five-year comparison of wear using oxidised zirconium and cobalt-chrome femoral heads in total hip arthroplasty: a multicentre randomised controlled trial. Bone Joint J 97-B, 883-889.

23. Sato T, Nakashima Y, Akiyama M, Yamamoto T, Mawatari T, Itokawa T, Ohishi M, Motomura G, Hirata M, Iwamoto Y (2012) Wear resistant performance of highly cross-linked and annealed ultra-high molecular weight polyethylene against ceramic heads in total hip arthroplasty. J Orthop Res 30, 2031-2037.

24. Garvin KL, White TC, Dusad A, Hartman CW, Martell J (2015) Low wear rates seen in THAs with highly crosslinked polyethylene at 9 to 14 years in patients younger than age 50 years. Clin Orthop Relat Res 473, 3829-3835. 
25. Australian Orthopaedic Association National Joint Replacement Registry (2016) Annual report 2016. AOA: Adelaide.

26. Cheung A, Yan CH, Fu H, Cheung MH, Chan PK, Chiu KY (2019) Ten- to sixteen-year follow-up of highly cross-linked polyethylene in total hip arthroplasty: What factors affect wear? J Arthroplasty 34, 2016-2021.

27. de Steiger R, Lorimer M, Graves SE (2018) Cross-linked polyethylene for total hip arthroplasty markedly reduces revision surgery at 16 years. J Bone Joint Surg Am 100, 1281-1288.

28. The New Zealand Joint Registry. Twenty year report: January 1999 to December 2018.

29. Swedish Hip Arthroplasty Register (2013) Annual report.

30. Johanson PE, Furnes O, Ivar Havelin L, Fenstad AM, Pedersen AB, Overgaard S, Garellick G, Mäkelä K, Kärrholm J (2017) Outcome in design-specific comparisons between highly crosslinked and conventional polyethylene in total hip arthroplasty. Acta Orthop 88, 363-369.

31. Davis ET, Pagkalos J, Kopjar B (2020) Polyethylene manufacturing characteristics have a major effect on the risk of revision surgery in cementless and hybrid total hip arthroplasties. Bone Joint J 102-B, 90-101.

32. Lim SJ, Yeo I, Park CW, Lee KJ, Min BW, Park YS (2019) High survivorship of highly cross-linked polyethylene in revision total hip arthroplasty: a minimum 10-year follow-up study. Arthroplasty 1, 16.

33. Kamada K, Takahashi Y, Tateiwa T, Shishido T, Masaoka T, Pezzotti G, Yamamoto K (2019) Influence of liner offset and locking mechanism on fatigue durability in highly cross-linked polyethylene total hip prostheses. J Biomedl Mater Res B Appl Biomater 108, 1993-2004.

34. Shin WC, Moon NH, Jeon SB, Suh KT (2019) Comparison of surgical outcomes between standard and elevated-rim highly cross-linked polyethylene acetabular liners in primary total hip arthroplasty with minimum 15-year follow-up: single-center, retrospective cohort study. J Arthroplasty 35, 1290-1296.

35. Bauze A, Agrawal S, Cuthbert A, de Steiger R (2019) Are hooded, crosslinked polyethylene liners associated with a reduced risk of revision after THA? Clin Orthop Relat Res 477, 1315-1321.

36. Malatray M, Roux JP, Gunst S, Pibarot V, Wegrzyn J (2017) Highly crosslinked polyethylene: a safe alternative to conventional polyethylene for dual mobility cup mobile component. A biomechanical validation. Int Orthop 41, 507-512.

37. Epinette JA, Harwin SF, Rowan FE, Tracol P, Mont MA, Chughtai M, Westrich GH (2017) Early experience with dual mobility acetabular systems featuring highly cross-linked polyethylene liners for primary hip arthroplasty in patients under fifty five years of age: an international multi-centre preliminary study. Int Orthop 41, 543-550.

38. D'Apuzzo MR, Koch CN, Esposito CI, Elpers ME, Wright TM, Westrich GH (2016) Assessment of damage on a dual mobility acetabular system. J Arthroplasty 31, 1828-1835.

39. Pritchett JW (2016) Hip resurfacing using highly cross-linked polyethylene: prospective study results at 8.5 years. Journal Arthroplasty 31, 2203-2208.

40. Amstutz HC, Takamura KM, Ebramzadeh E, Le Duff MJ (2015) Highly cross-linked polyethylene in hip resurfacing arthroplasty: long-term follow-up. Hip Int 25, 39-43.
41. Treacy R, Holland JP, Daniel J, Ziaee H, McMinn D (2019) Preliminary report of clinical experience with metal-on-highlycrosslinked-polyethylene hip resurfacing. Bone Joint Res 8, 443-450.

42. Tower SS, Currier JH, Currier BH, Lyford KA, Van Citters DW, Mayor MB (2007) Rim cracking of the cross-linked longevity polyethylene acetabular liner after total hip arthroplasty. J Bone Joint Surg Am 89, 2212-2217.

43. Duffy GP, Wannomae KK, Rowell SL, Muratoglu OK (2009) Fracture of a cross-linked polyethylene liner due to impingement. J Arthroplasty 24, 158.e15-158.e1.58E19.

44. Blumenfeld TJ, McKellop HA, Schmalzried TP, Billi F (2011) Fracture of a cross-linked polyethylene liner: a multifactorial issue. J Arthroplasty 26, 666.e5-666.e6.66E8.

45. Ast MP, John TK, Labbisiere A, Robador N, Valle AG (2014) Fractures of a single design of highly cross-linked polyethylene acetabular liners: an analysis of voluntary reports to the United States Food and Drug Administration. J Arthroplasty 29, 1231-1235.

46. Furmanski J, Anderson M, Bal S, Greenwald AS, Halley D, Penenberg B, Ries M, Pruitt L (2009) Clinical fracture of crosslinked UHMWPE acetabular liners. Biomaterials 30, 5572-5582.

47. Furmanski J, Kraay MJ, Rimnac CM (2011) Crack initiation in retrieved cross-linked highly cross-linked ultrahigh-molecularweight polyethylene acetabular liners: an investigation of 9 cases. J Arthroplasty 26, 796-801.

48. Bates MD, Mauerhan DR (2015) Early fracture of a vitamin-Einfused, highly cross-linked polyethylene liner after total hip arthroplasty: a case report. JBJS Case Connector 5, e65.

49. Brazier BG, Mesko JW (2018) Superior rim fracture of a vitamin E-infused highly cross-linked polyethylene (HXLPE) liner leading to total hip arthroplasty revision. Arthroplasty today 4, 287-290.

50. Kahlenberg CA, Menken L, Ranawat AS, Rodriguez JA (2020) Early failure of a modern moderately cross-linked polyethylene acetabular liner. Arthroplasty Today, 1-3.

51. Thomas WC, Parvataneni HK, Vlasak RG, Gray CF (2020) Early polyethylene failure in a modern total hip prosthesis: a note of caution. J Arthroplasty 35, 1297-1302.

52. Anand R, Graves SE, de Steiger RN, Davidson DC, Ryan P, Miller LN, Cashman K (2011) What is the benefit of introducing new hip and knee prostheses? J Bone Joint Sug Am 93, 51-54.

53. Nieuwenhuijse MJ, Nelissen RG, Schoones JW, Sedrakyan A (2014) Appraisal of evidence base for introduction of new implants in hip and knee replacement: a systematic review of five widely used device technologies. BMJ (Clinical research ed.) 349, g5133.

54. López-López JA, Humphriss RL, Beswick AD, Thom H, Hunt LP, Burston A, Fawsitt CG, Hollingworth W, Higgins J, Welton NJ, Blom AW, Marques E (2017) Choice of implant combinations in total hip replacement: systematic review and network meta-analysis. BMJ (Clinical research ed.) 359, j4651.

55. Harris WH, Muratoglu OK (2019) The role of crosslinked polyethylene in reducing aggregated costs of total hip arthroplasty in the United States. J Arthroplasty 34, 1089-1092.

56. Malchau H, Bragdon CR, Muratoglu OK (2011) The stepwise introduction of innovation into orthopedic surgery: the next level of dilemmas J Arthroplasty 26, 825-831. 